\title{
Characterization of Olfactory Ensheathing Glial Cells Cultured on Polyurethane/Polylactide Electrospun Nonwovens
}

\author{
Jakub Grzesiak, ${ }^{1}$ Ryszard Fryczkowski, ${ }^{2}$ Anna Lis, ${ }^{3}$ Dariusz Szarek, ${ }^{4}$ \\ Jadwiga Laska, ${ }^{3}$ and Krzysztof Marycz ${ }^{1}$ \\ ${ }^{1}$ Electron Microscopy Laboratory, University of Environmental and Life Sciences Wroclaw, Kozuchowska 5b, 51-631 Wroclaw, Poland \\ ${ }^{2}$ Faculty of Materials and Environmental Sciences, ATH University of Bielsko-Biala, Willowa 2, 43-309 Bielsko-Biala, Poland \\ ${ }^{3}$ Faculty of Materials Science and Ceramics, AGH University of Science and Technology, Mickiewicza 30, 30-059 Krakow, Poland \\ ${ }^{4}$ Department of Neurosurgery, Lower Silesia Specialist Hospital of T. Marciniak, Emergency Medicine Center, \\ Traugutta 116, 50-420 Wroclaw, Poland
}

Correspondence should be addressed to Jakub Grzesiak; grzesiak.kuba@gmail.com and

Krzysztof Marycz; krzysztofmarycz@interia.pl

Received 8 January 2015; Revised 14 March 2015; Accepted 15 March 2015

Academic Editor: Jin Huang

Copyright (C) 2015 Jakub Grzesiak et al. This is an open access article distributed under the Creative Commons Attribution License, which permits unrestricted use, distribution, and reproduction in any medium, provided the original work is properly cited.

\begin{abstract}
The aim of this research was to evaluate novel biomaterials for neural regeneration. The investigated materials were composed of polyurethane (PU) and polylactide (PLDL) blended at three different w/w ratios, that is, 5/5, 6/4, and 8/2 of PU/PLDL. Ultrathin fibrous scaffolds were prepared using electrospinning. The scaffolds were investigated for their applicability for nerve regeneration by culturing rat olfactory ensheathing glial cells. Cells were cultured on the materials for seven days, during which cellular morphology, phenotype, and metabolic activity were analysed. SEM analysis of the fabricated fibrous scaffolds showed fibers of a diameter mainly lower than $600 \mu \mathrm{m}$ with unimportant volume of protrusions situated along the fibers, with nonsignificant differences between all analysed materials. Cells cultured on the materials showed differences in their morphology and metabolic activity, depending on the blend composition. The most proper morphology, with numerous $75^{+}$and $\mathrm{GFAP}^{+}$cells present, was observed in the sample $6 / 4$, whereas the highest metabolic activity was measured in the sample $5 / 5$. However, none of the investigated samples showed cytotoxicity or negatively influenced cellular morphology. Therefore, the novel electrospun fibrous materials may be considered for regenerative medicine applications, and especially when contacting with highly sensitive nervous cells.
\end{abstract}

\section{Introduction}

Nervous system is well known for its relatively low ability to regenerate comparing with other systems and organs. Posttraumatic or disease caused injury in nervous system is always very debilitating lesion. For this reason, search for new treatment solutions, implants that will match in the best way with neuroregeneration process requirements, is intensively continued [1-8]. The common methodology in tissue engineering is to mimic the architecture of the native extracellular matrix (ECM), which plays a significant role in regulating cellular behaviour [1-7]. The interest in fibrous scaffolds for regenerative medicine is based on the electrospun micro-/nanofibers of high resemblance to the hierarchical fibrillary arrangement of the ECM [1-7].

Fibrous meshes prepared by electrospinning technique have numerous advantages, such as high specific surface area, inordinate porosity, low density, high gas and liquid permeability, good mechanical properties, and possibility of surface functionalization [9-15]. High porosity and fibrous structure facilitate cell adhesion and infiltration [9], neurite contact guidance [10-12], axon penetration [12, 13], and diffusion of nutrients and waste substances, all of which act to enhance integration of the polymer scaffold with the 
tissue [9-13]. Polymers processed by the electrospinning technique are used with considerably increasing interest for both central and peripheral neural tissue engineering ([1, 16-18] and references cited therein).

Conventionally, electrospun fibrous scaffolds have been fabricated from sole polymer sources [5, 11, 19-30], but recently combinations of polymers have been used to create polyblend fibers $[1,10,14-36]$. Polyurethanes (PU) and polylactide (PLDL) are known to be used as biodegradable scaffolds (in vitro) $[25,30]$ and implants (in vivo) $[37,38]$. Polyurethanes have been extensively applied for different tissues engineering and clinical applications due to their biocompatibility $[30,35,37,38]$, suitable mechanical properties, and excellent elasticity [29, 30, 37, 38]. Polylactide was found to be attractive for regenerative medicine application because of its high biocompatibility and biodegradability; however, its rigidness is usually a disadvantage [20, 33, 37, 38]. Recently, polyurethane and polylactide compositions were used for the manufacture of tube-shaped implants for sciatic nerve repair $[37,38]$. Biodegradable polyurethane is an elastic material and more hydrophilic (and thus slower degrading). Biodegradable polyurethanes are ideal candidates for fabricating neural tissue engineering scaffold, with mechanical properties akin to resilient soft tissues. In contrast, bioresorbable polylactide is a rigid polymer, more hydrophilic (and thus faster degrading), and easier in processing. Polylactides are widely proposed for the manufacturing of fibrous scaffolds for neural cell culture, as well as polyurethane. The two biocompatible polymers were combined with different ratios, because it is important to control the mechanical properties and degradation rate of a scaffold as the scaffold should degrade in appropriate matching rate as nerve tissue growth. The PU/PLDL blend can be either rigid or flexible, depending on the polymer ratio, and is a composite material of choice for a broad range of tissue engineering application such as nerve conduits. On the basis of previous research [37] and in vitro test [publication in press], it was found that a PU/PLDL blend is suitable for peripheral nerve regeneration and cultivation of OECs. Following experiments has led to choose the right blend composition that matched surgical requirements, implantation bed, and regenerating tissue optimally. It was also found that it is possible to achieve a variety of properties of the implant by changing the polymer composition. Good results from those studies were reasons to examine applicability of these polymers in studies concerning the central nervous system.

The biological evaluation of novel biomaterials can be based on different research models, including primary mammalian cell cultures. Usually the materials designed for neural tissue are being evaluated using neural cell lines, like Schwann cells, astrocytes, or neurons [39-43]. The determination of particular cellular responses to tested biomaterials delivers valuable information about materials biocompatibility and possible cytotoxic character prior to in vivo research. The cell adhesion support is one of the most essential characteristics, determining the ability of stem or precursor cells to colonize the material before or after its transplantation $[44,45]$. In materials designed, for example, for peripheral nerve regeneration, their ability for supporting the adhesion of Schwann cells is highly desired, as these cells are directly involved in restoration of broken neural tracts [46]. Moreover, the cellular morphology and phenotype cannot be altered in response to the biomaterial [47].

Olfactory ensheathing cells (OEC) have been found to be promising regenerative medical tool for regeneration in central nervous system injuries. Olfactory ensheathing glial cells are present within the outer layers of olfactory bulb and possess the ability to support neural and glial cell differentiation, most importantly regrowth of severed long neural tracts. The olfactory ensheathing oligodendrocytes resemble the Schwann cells, while they ensheath the nonmyelinated neurons and adopt the bipolar morphology in culture. OEC may also be characterized by the presence of glial fibrillary acidic protein (GFAP) and the p $75^{\mathrm{NTR}}$ - the receptor for neurotrophin [48]. The application of these cells in experimental treatment of damaged neural tissue resulted in promising effects in both animal and human studies [4951]. They have also been utilized for in vitro evaluation of various biomaterials [52-54]. In the future, as the use of OEC will be better known, they may be implemented in bigger posttraumatic injuries of nervous system that come with extensive tissue loss. In these conditions OEC have to be implanted with artificial ECM that will, at least temporarily, bridge the deficiency. For this use electrospun fibers are increasingly investigated.

In our work we employed the electrospinning method to prepare various polyurethane/polylactide fibrous scaffolds for in vitro colonization with olfactory ensheathing glial cells. During seven-day culture, dependence of cell metabolic activity and morphology on altered compositions of PU/PLDL fibrous nonwovens were investigated.

\section{Materials and Methods}

2.1. Materials. The polymer materials used in our study were polyurethane (PU) and poly(L-lactide-co-D,L-lactide) (PLDL), with molar ratio L-lactide to D,L-lactide 80:20. Biodegradable elastomeric polyurethane was purchased from BAYER Material Science. Polylactide PURASORB PLDL8038 was purchased from Purac Biochem BV, Netherlands. Dimethylformamide (DMF), as a solvent, and sterile-filtered water for molecular biology and cell culture were purchased from Sigma-Aldrich.

2.2. Electrospinning of PU/PLDL Nonwovens. A series of PU/PLDL solutions with different mixing ratios were prepared by dissolving polymer granules in DMF by magnetic stirring for $72 \mathrm{~h}$ at $40^{\circ} \mathrm{C}$. The concentration of the solutions was $7.5 \%$. The polyurethane-to-polylactide $\mathrm{w} / \mathrm{w}$ ratios were $8: 2,6: 4$, and $5: 5$. The PU/PLDL solutions were distributed by a $5 \mathrm{~mL}$-syringe pump at a constant flow rate of $0.1 \mathrm{~mL} / \mathrm{h}$. The distance between the spinneret (steel needle, diameter: $0.5 \mathrm{~mm}$ ) and a collector (aluminium foil disc) was $15 \mathrm{~cm}$ and the voltage was $20 \mathrm{kV}$. All the PU/PLDL solutions were electrospun under the same laboratory conditions at $40^{\circ} \mathrm{C}$, and fibers of various morphologies were produced. The electrospun PU/PLDL nonwovens were dried at room 
temperature, then circles of the diameter of $15 \mathrm{~mm}$ intended for cell culture were cut out and detached from aluminium foil, washed two times in sterile-filtered water, and stored for 24 hours at room temperature and then at $25^{\circ} \mathrm{C}$ under vacuum to remove the remaining solvent. The samples were sterilized via hydrogen peroxide cold plasma and stored in sterile packages (SIGMA-EN 868/ISO 11607, $\mathrm{H}_{2} \mathrm{O}_{2}$ plasma) for the subsequent use.

2.3. Characterization of PU/PLDL Nonwovens. Morphology of the electrospun fibers and fiber diameter were studied using a scanning electron microscope (Nova Nano SEM 200, FEI Europe Company, EVO LS15, Zeiss). Before observation, the scaffolds were coated with gold or carbon using a sputter coater. The diameter of the individual fiber was measured on the SEM micrographs (magnification 10000x) using image analysis software.

SEM images were taken for ten different fragments of each nonwoven. All the data presented are expressed as mean \pm standard deviation (SD) of the mean. Statistical differences were determined by Student's ten-sample $t$-test. Differences were considered statistically significant at $P \leq 0.05$.

The surface wettability tests of polymer films (reference samples) and electrospun nonwovens were characterized by measuring the contact angle by means of the static sessile drop method. The measurements were performed by a contact angle goniometer (DSA $10 \mathrm{Mk} 2$, Kruss) of sterile distilled water droplet on the fibrous scaffolds, placed on the stainless-steel holder surfaces, at room temperature. The values of the contact angle were obtained by averaging the values of at least ten measurements for each sample.

2.4. Biological Evaluation. The biological evaluation of obtained materials included the determination of metabolic activity and morphological characterization of cultured olfactory ensheathing glial cells, as the population of high regenerative properties.

2.4.1. Cell Isolation. Biological experiments were approved by the Local Ethics Committee. Glial cells derived from olfactory bulb were isolated using the modified procedure described earlier $[48,55]$. Olfactory bulbs dissected from three neonatal pups' brains were placed in Hank's balanced salt solution (HBSS). Tissues were extensively washed, minced with scissors, and incubated in $0.2 \%$ collagenase for 10 minutes at $37^{\circ} \mathrm{C}$. The material was subsequently fragmented by syringe needles (18 G, $20 \mathrm{G}$, and $22 \mathrm{G}$ ) and washed again in HBSS. Cells were centrifuged for 5 minutes at $300 \times \mathrm{g}$ and resuspended in fresh DMEM/F12:Ham supplemented with $10 \%$ FBS and $1 \%$ of penicillin/streptomycin/amphotericin b solution. Cells were plated and cultured in T-75 culture flasks at $37^{\circ} \mathrm{C} / 5 \% \mathrm{CO}_{2}$ in humidified incubator for 18 hours, after which the media with floating cells were transferred to the new T-75 flasks for 7 days, with addition of fresh medium after 3 days. After this time, cells were collected from primary cultures using TrypLE express, evaluated for viability and number using trypan blue exclusion method with Burker counting chamber, and seeded on experimental materials placed in a 24 -well plate, at a concentration of $5 \times 10^{4}$ cells per well, in triplicate $(n=3$, cells were isolated from three individuals).

2.4.2. Viability Assay. Glial cells were evaluated for their metabolic activity in the presence of tested materials, using Alamar Blue assay procedure described earlier [56]. Activity was determined at days 1,4 , and 7 of culture. Cells cultured in wells without the tested materials were used for the control. In brief, cells were incubated with the resazurin solution (10\% in culture medium) for 2 hours, after which media were collected and transferred to the 96-well plate for absorbance measurements. The absorbance was determined using spectrometer (SPECTROstar Nano, BMG LABTECH) at the specific wavelengths, that is, $600 \mathrm{~nm}$ for resazurin and $690 \mathrm{~nm}$ as the plate background absorbance. Experiments were carried out with two repeats. Metabolic factor (MF) for cultures with tested nonwovens was determined in relation to the control cultures using algorithm described previously [57]. Obtained values were presented as arbitrary units. The normalization of the data to the control culture was used to determine whether the presence of biomaterials in cultures resulted in an increase $(\mathrm{MF}>1)$ or a decrease $(\mathrm{MF}<1)$ in the rate of glial cell metabolic activity. The results were verified for statistical significance using the ANOVA one-way test (between groups) and Student's $t$-test (between control and any other group). The differences were considered as statistically significant when $P<0.05$ and lower.

2.4.3. Morphological Investigation. After seven days culture cells were fixed in ice-cold 4\% paraformaldehyde (PFA) for 15 minutes at room temperature for fluorescent microscopy and in $2.5 \%$ glutaraldehyde for 1 hour at room temperature for scanning electron microscopy (SEM).

PFA-fixed cells were triple-washed with HBSS supplemented with $2 \%$ of bovine serum albumin (BSA) and incubated with HBSS supplemented with $10 \%$ of FBS for 1 hour at room temperature for nonspecific antigen binding sites blocking. In the next step, cells were permeabilized with $0.05 \%$ of Triton X-100 dissolved in HBSS+2\% BSA for 15 minutes at room temperature, followed by their incubation with primary antibodies (mouse antiglial fibrillary acidic protein (GFAP) IgG, $5 \mu \mathrm{g} / \mathrm{mL}$ in HBSS supplemented with $0.01 \%$ of Triton X-100 and $2 \%$ of BSA; rabbit anti-p $75^{\mathrm{NTR}}$ (neurotropin receptor) IgG, $5 \mu \mathrm{g} / \mathrm{mL}$ in HBSS supplemented with $0.01 \%$ of Triton X-100 and $2 \%$ of BSA; all purchased from Sigma) for 1 hour at $37^{\circ} \mathrm{C}$. After triple washing, cells were incubated with secondary, fluorescent antibodies (goat anti-mouse IgG conjugated with atto594, $2 \mu \mathrm{g} / \mathrm{mL}$ in HBSS supplemented with $0.01 \%$ of Triton X-100 and 2\% of BSA; goat anti-rabbit IgG conjugated with atto $488,2 \mu \mathrm{g} / \mathrm{mL}$ in HBSS supplemented with $0.01 \%$ of Triton X-100 and $2 \%$ of BSA; purchased from Sigma) for 1 hour at $37^{\circ} \mathrm{C}$. For negative control staining, samples were incubated with secondary antibodies without incubation with primary antibodies. After triple washing, cells were subsequently incubated with DAPI $(5 \mu \mathrm{g} / \mathrm{mL})$ for 5 minutes at room temperature for nuclei counterstaining. After the final triple washing, materials 
TABLE 1: Measurement results of initial contact angle of cast films and nonwovens obtained from pure PU and different PU/PLDL blends.

\begin{tabular}{lcccc}
\hline Sample type & & \multicolumn{3}{c}{ Contact angle [ ${ }^{\circ}$ ] } \\
& PU & PU/PLDL 8/2 & PU/PLDL 6/4 & PU/PLDL 5/5 \\
\hline Cast film & $126.8 \pm 1.2$ & $81.3 \pm 0.9$ & $70.2 \pm 0.4$ & $65.4 \pm 1.6$ \\
Nonwoven & $121.0 \pm 0.7$ & $73.6 \pm 0.6$ & $58.4 \pm 1.3$ & $54.3 \pm 2.4$ \\
\hline
\end{tabular}

with stained cells were placed on microscopic glass slides, covered with Fluoromount (Sigma), and observed using the inverted, fluorescent microscope (AxioObserver, Zeiss). Documentation was made with digital camera (Cannon PowerShot A640). The obtained pictures were merged using ImageJ software.

Electron microscopic observations and material preparation were performed according to the protocol described by Marędziak et al. [58]. Samples fixed for SEM were triple washed with phosphate buffer $(\mathrm{pH}=7.4)$ and rinsed with ultrapure water for 1 minute. Preparations were then dehydrated using graded ethanol series (from 50\% to $99.8 \%$ every $10 \%)$, sputtered with gold, and observed in field emission scanning electron microscope. The cells were then pseudocoloured using ImageJ for facilitating the recognition of cells.

\section{Results and Discussion}

3.1. Characterization of PU/PLDL Nonwovens. PU/PLDL blends differing with the contents of the polymers were investigated, as PLDL is rigid and PU soft and elastic optimum mechanical properties can be achieved by blending the polymers. Detailed studies of the material have been performed recently, and the results will be published separately [publication in press]. On the basis of these results, compositions of PU and PLDL were chosen for the presented studies, namely, w/w $8 / 2,6 / 4$, and 5/5. Depending on the PU to PLDL ratio in a blend, the scaffolds differed with mechanical properties. For the neural cells soft substrates enriched in elastic PU seem to be more appropriate. It was already tested and confirmed that the films containing $8 / 2$ PU/PLA are very handy for surgeons. Electrospun fibrous scaffolds as a substrate for OEC culture were fabricated using solution electrospinning. SEM images of the PU/PLDL fibrous scaffolds are shown in Figure 1. Micrographs of the electrospun scaffolds show fibers of microscale diameter creating $3 \mathrm{D}$ structures with a significant part of voids in between the fibers. It is visible that the introduction of different amounts of rigid PLDL and flexible PU into the solution resulted in the creation of networks with moderately different nano-/microfibrous structures. Random oriented PU/PLDL fibers showed diameters that ranged from 20 to $900 \mathrm{~nm}$. Fiber diameter distribution is presented in Figure 1. In all cases, spherical/ellipsoid or circle/ellipse defects (i.e., beads-on-string structure) were observed. Scaffolds with a more regular fibrous structure were observed for PU/PLDL $8 / 2$ blend. The decrease of the PLDL content promoted creation of more regular fibrous scaffolds.

Water contact angle was measured for determination of hydrophilic properties of the samples. The hydrophilicity of the fibrous scaffolds might play an essential role in the determination of their usability as cell culture substrates [59]. Table 1 summarized the contact angle values of polyurethane and PU/PLDL blends cast films and electrospun nonwovens. The contact angle of the polyurethane fibrous scaffold was about $121^{\circ}$. The contact angle values for PU/PLDL blends decreased with the increase of PLDL content. The contact angle for PU/PLDL 5/5 composite was 54.3 . The contact angle values of PU/PLDL fibrous scaffolds were lower than that of PU/PLDL cast film, which can be explained by the difference in the roughness of the surface.

\subsection{Biological Evaluation}

3.2.1. Viability Assay. Olfactory ensheathing cells cultured on the investigated materials showed differences in metabolic activity (viability), concerning the composition of the material. All research group cultures showed statistically significant differences in metabolic activity $(P<0.01)$ in comparison to the polystyrene well control. The highest average metabolic activity was noticed in group OEC cultured on scaffolds containing 5/5 weight ratio of PU/PLDL, while the lowest when the ratio was $8 / 2$, with statistically significant differences noticed between all groups (Figure 2(d)). The metabolic activity was higher in samples with lower polyurethane content during first days of culture (Figures 2(a) and 2(b)), but after the 7th day, the highest metabolic factor was noticed in sample $8 / 2$; however, no statistically significant differences between any groups were noticed (Figure 2(c)). The increased metabolism in samples with higher polylactide concentration was rather not an effect of the presence of lactic acid as a product of biomaterial degradation. This monomer may be initially released at higher quantities during first days due to PLDL degradation; however, it should not influence cell viability. The lactic acid is one of the cell metabolism products during in vitro culture conditions, and its cytotoxicity has been observed only at high concentrations and correlated with a significant decrease in $\mathrm{pH}$ [59]. In this experiment, the significant changes in $\mathrm{pH}$ were excluded by the addition of HEPES buffer to the culture medium and proper medium change intervals, which was controlled by observations of phenol red-containing medium color. Therefore, the reason for the statistically significant differences in cell metabolic activity lays in different physical characteristics of the scaffolds resulting from different polyurethane/polylactide concentrations. One of the influencing properties can be wettability of the fibers differing for different PU/PLDL contents. Contact angles measured for films of the examined compositions are visibly different. For example, contact angle of films containing 


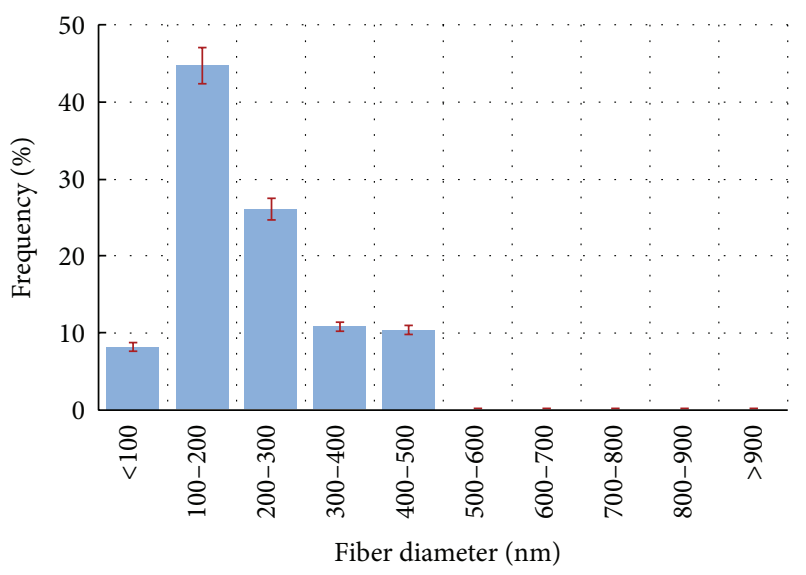

- PU/PLDL 5/5

(a)

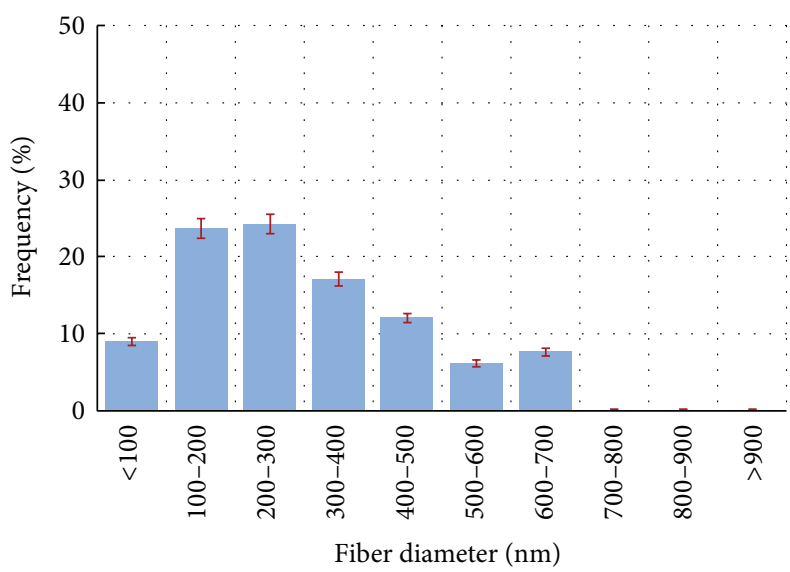

[ PU/PLDL 6/4

(c)

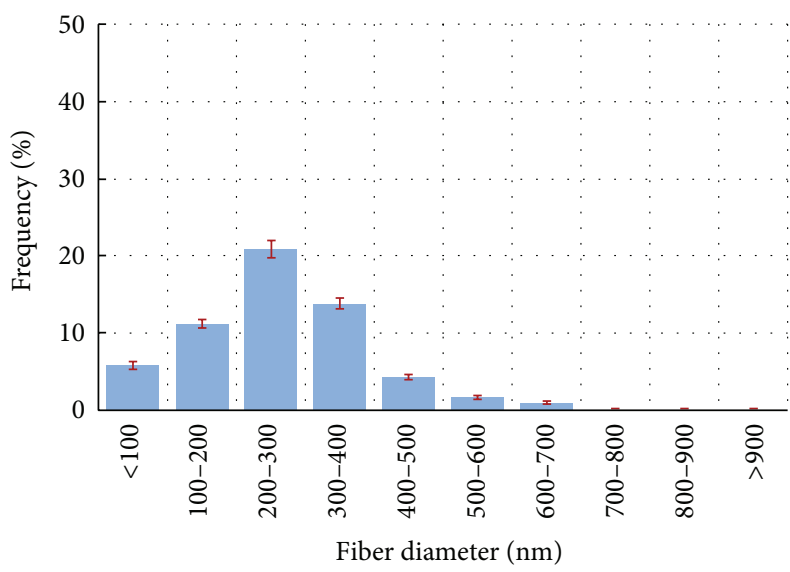

- PU/PLDL 8/2

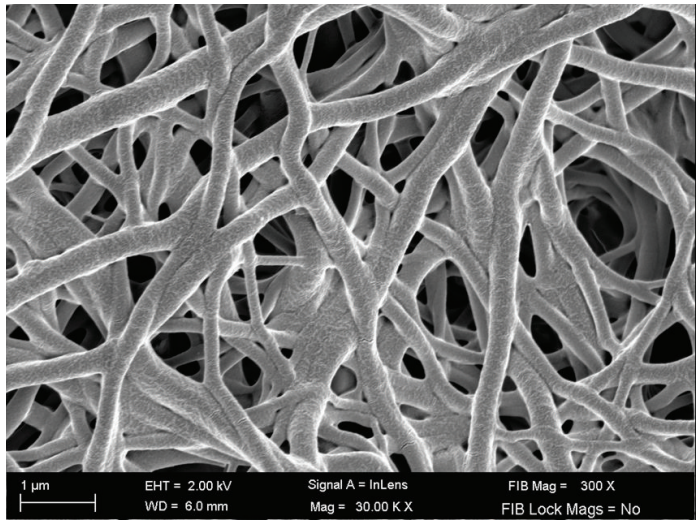

(b)

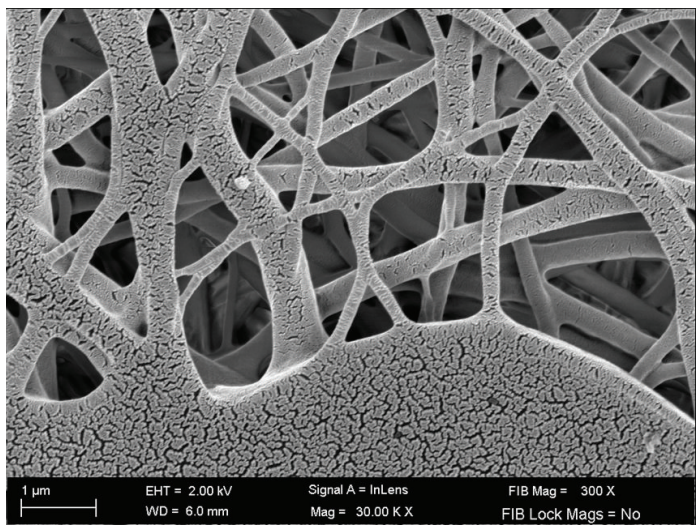

(d)

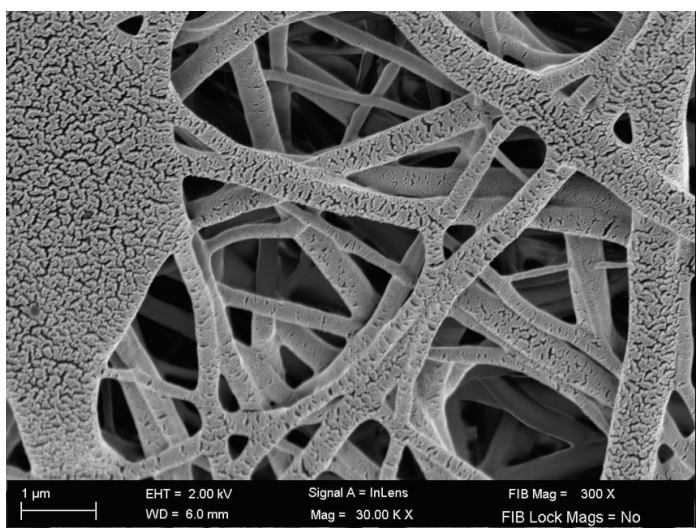

(f)

FIGURE 1: SEM micrographs of PU/PLDL nonwovens (right) and bar graphs (left) displaying fiber diameters. Weight ratios of PU/PLDL: (a, b) $5 / 5$, (c, d) $6 / 4$, and (e, f) $8 / 2$. Thickness of the fibers depends on the blend composition; that is, the more PU in the blend the thicker and more regular the fibers. Some beads are created along the fibers; however, they were not taken into consideration in the average diameter calculation. 


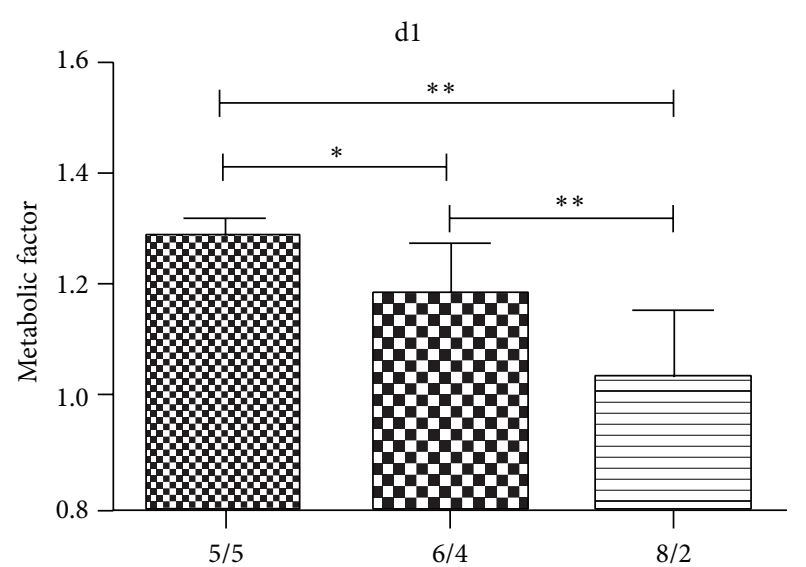

(a)

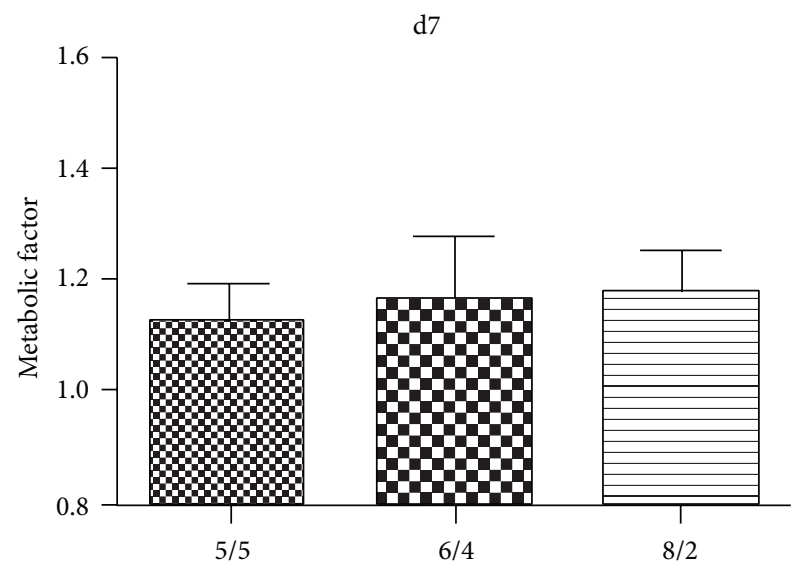

(c)

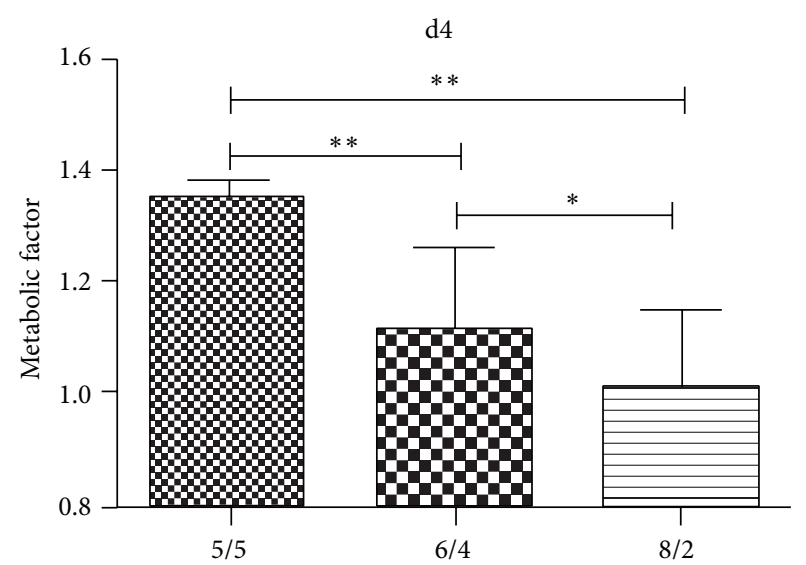

(b)

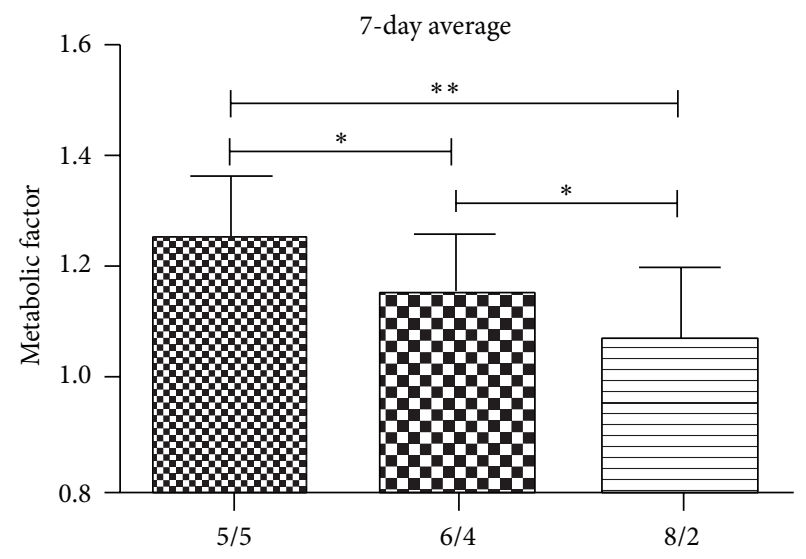

(d)

FIGURE 2: Metabolic factors of OEC on PU/PLDL electrospun scaffolds of various PU/PLDL w/w ratios after 1, 4, and 7 days in culture (graphs a, b, and c, resp.), and metabolic factors averaged from whole culture period (d); ${ }^{*} P<0.05,{ }^{* *} P<0.01, n=3$.

$80 \mathrm{wt} \%$ of PU and $20 \mathrm{wt} \%$ of PLDL ranges from 80 to $81^{\circ}$, while that of films containing $50 \mathrm{wt} \%$ of each component ranges from 52 to $56^{\circ}$. It is noteworthy that after seven days of culture, the differences in metabolic activity between all groups were prominently decreased, and no statistically significant differences were noticed between all groups $(P>$ $0.05)$. It is most probably caused by creation of cell monolayer on investigated materials, which modified and uniformed the characteristic of surface for newly occurring cells after cell division. Moreover, the increased proliferative activity in samples 5/5 and 6/4 during first four days resulted in achieving full confluence faster than in sample $8 / 2$; therefore, the decrease in proliferation in these two samples was observed earlier due to the contact inhibition. The detailed results are shown in Figure 2.

3.2.2. Morphological Investigation. Among the cultured glial cells, both GFAP- and p75-positive cells were detected. Cells showed the presence of specific GFAP in all investigated samples, as well as in control cultures. In control cultures, GFAP $^{+}$cells were single, of bipolar elongated shape with a few filopodia. In material containing PU/PLDL 5/5, GFAP ${ }^{+}$ cells were elongated or formed cellular aggregates. In group cultured on 6/4 blend fibers, cells were less elongated, with lower number of extracellular processes than in $5 / 5$ group. Moreover, the cellular aggregates were not visible. In group cultured on 8/2 PU/PLDL scaffolds, GFAP ${ }^{+}$cells were grouped and flattened and multipolar. Cell aggregates were present in this case. Cells in control culture had characteristic, bipolar spindle shape with high p75 signal detected on their surface. Moreover, cells with fibroblastic morphology were positive for p 75 only at the nuclear area. Among all p $75^{+}$cells derived from olfactory bulb, there are two subpopulations of cells: p75-strong $\left(\mathrm{p} 75^{+S}\right)$ and p75-weak $\left(\mathrm{p} 75^{+\mathrm{W}}\right)$, with different functionality within the olfactory system, as it was recently observed by Honoré et al. [48]. Therefore, as observed in our experiments cells exhibited expected characteristics. In 5/5 group, cells were elongated but not spindle shaped, rather more irregular. The number of $\mathrm{p} 75^{+S}$ cells was prominently lower than in control culture, and the cell aggregates were present in this group. In the scaffolds based on 6/4 PU/PLDL, $\mathrm{p} 75^{+S}$ cells were evenly distributed and elongated, with spindle shaped form and bipolar morphology. In this group, the number of $\mathrm{p} 75^{+\mathrm{W}}$ cells was considered as 

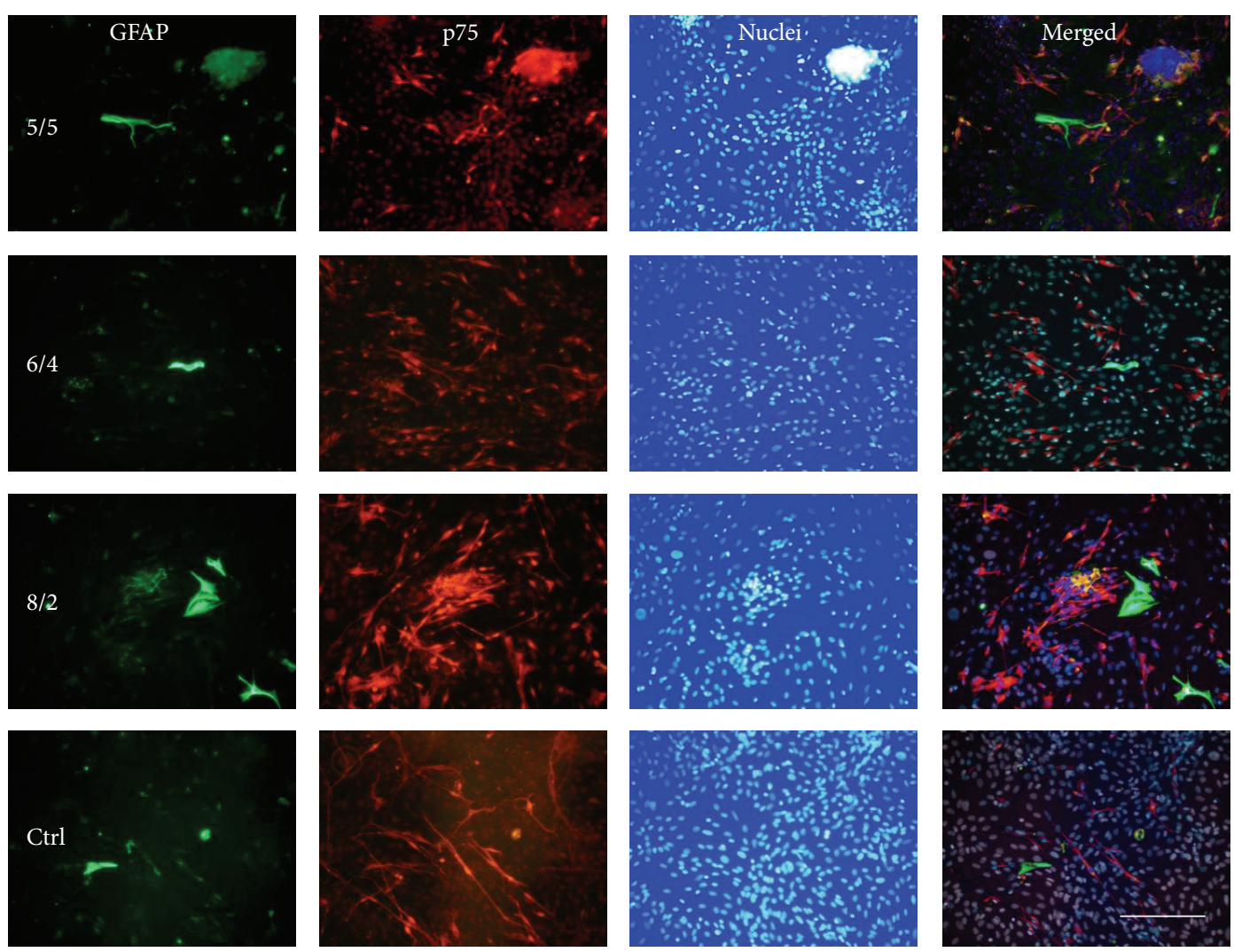

FIGURE 3: The immunofluorescence staining of olfactory bulb-derived glial cells grown on all investigated biomaterials and on control for seven days: 5/5 PU/PLDL (5/5), 6/4 PU/PLDL (6/4), 8/2 PU/PLDL (8/2), and polystyrene well culture (ctrl); GFAP ${ }^{+}$cells stained in green, $\mathrm{p} 75^{+}$cells stained in red, and nuclei stained in blue. Epifluorescent microscope, magnification 100x, scale bar $=250 \mu \mathrm{m}$.

moderate. Cells cultured on materials $8 / 2$ were elongated, but clustered and tangled, and the clusters were strongly positive for $\mathrm{p} 75$. The $\mathrm{p} 75^{+\mathrm{W}}$ cells were also present and exhibited the fibroblastic-like morphology (Figure 3).

SEM observations revealed that cells adhered to all investigated materials. In sample $5 / 5$, cells were of flattened morphology, with low number of elongated cells. In this sample, cells covered the material fibers and it was easy to distinguish cells from biomaterial. In sample $6 / 4$, cells were of various morphology, among flattened cells; observations revealed also cells with elongated bodies, morphologically similar to cultured Schwann cells investigated by Yuan et al. [60]. Cells' extensions adopted morphology similar to the biomaterial, so distinguishing them from investigated material was more difficult than in sample 5/5. Cells cultured on sample $8 / 2$ showed both flattened and elongated form. The similarity of cell extensions to the surface of investigated materials was lower than in sample 6/4 (Figure 4).

\section{Conclusions}

Fibrous polyurethane/polylactide scaffolds were fabricated using solution electrospinning technique. The mean diameters of the fibers were ranging from 20 to $900 \mathrm{~nm}$ depending on PU/PLDL composition. It was observed that the content of PLDL with respect to PU in a blend noticeably influenced the final scaffold microstructure, fiber diameter, and mutual arrangement. Higher amounts of PLDL resulted in the formation of more irregular fibrous structure, with higher number of defects in the form of beads, relatively brittle and twisted fibers. The biological evaluation using the olfactory ensheathing cells revealed that none of investigated materials induced the cytotoxic effect on cells. Moreover, all tested materials supported the adhesion of glial cells and did not alter their phenotype. The differences in biological effects between materials were observed in the metabolic activity of cells, with the highest cell viability noticed on sample 5/5. The differences in cellular morphology were considered as not significant and may be connected with differences in wettability of the materials. Therefore, these nonwovens electrospun from PU/PLDL blends may be found as promising scaffolds for olfactory ensheathing cells or in nervous tissue regeneration.

\section{Conflict of Interests}

The authors declare that there is no conflict of interests regarding the publication of this paper. 


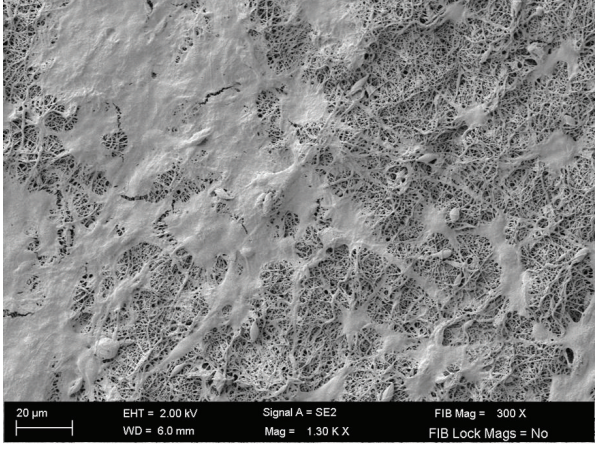

(a)

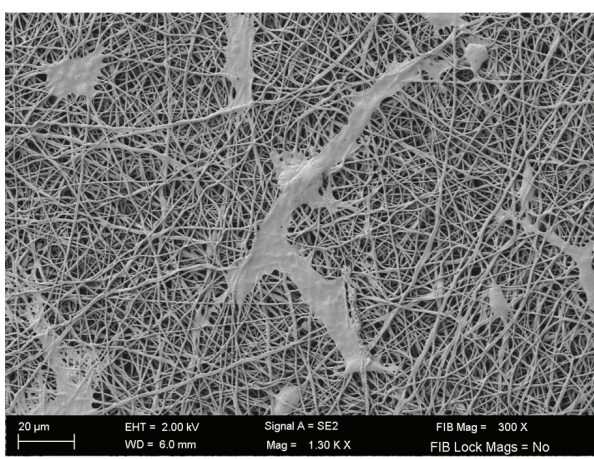

(c)

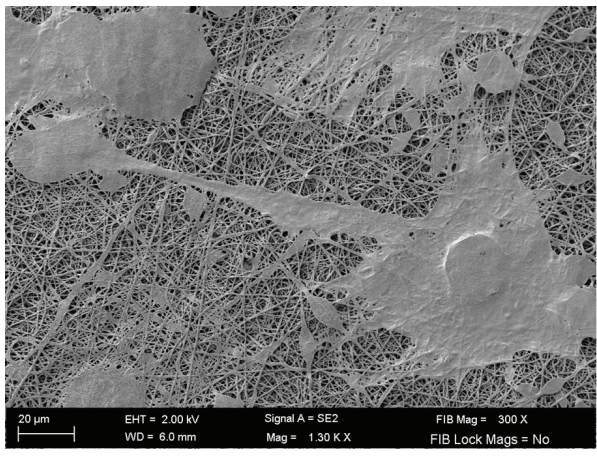

(e)

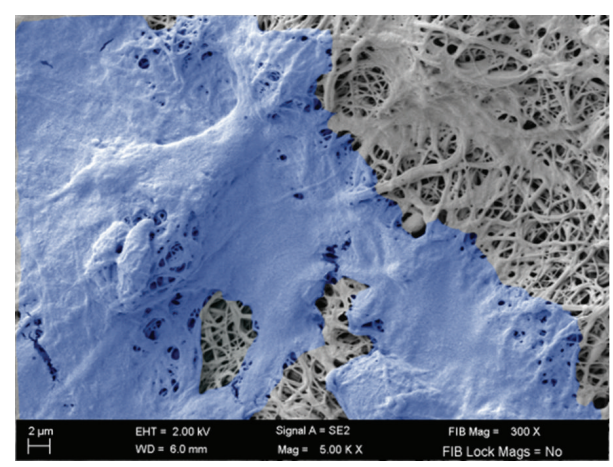

(b)

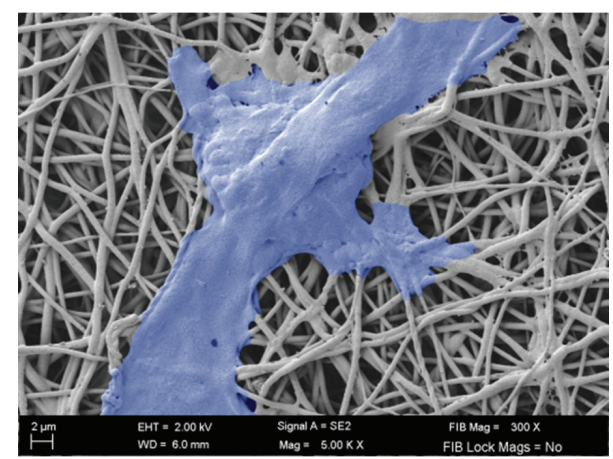

(d)

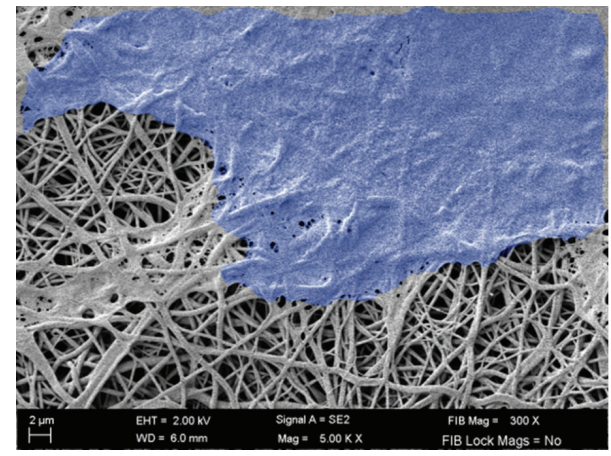

(f)

Figure 4: The micrograph presenting glial cells which adhere to material 5/5 PU/PLDL (a, b), 6/4 PU/PLDL (c, d), and 8/2 PU/PLDL (e, f); magnifications 1300x (a, c, e) and 5000x (b, d, f). Pseudocoloured images distinguish cells from biomaterials on pictures (b), (d), and (f) (blue). Scanning electron microscope, magnifications 1300x (a, c, e) and 5000x (b, d, f), scale bars presented on micrographs.

\section{Acknowledgment}

This research was financially supported by National Center of Science, Poland (Grants nos. 2011/01/B/STB8/07795 and N N403176540).

\section{References}

[1] Y.-S. Lee and T. L. Arinzeh, "Electrospun nanofibrous materials for neural tissue engineering," Polymers, vol. 3, no. 1, pp. 413426, 2011.

[2] D. Han and K. C. Cheung, "Biodegradable cell-seeded nanofiber scaffolds for neural repair," Polymers, vol. 3, no. 4, pp. 1684-1733, 2011.
[3] J. He, X.-M. Wang, M. Spector, and F.-Z. Cui, "Scaffolds for central nervous system tissue engineering," Frontiers of Materials Science, vol. 6, no. 1, pp. 1-25, 2012.

[4] J. T. S. Pettikiriarachchi, C. L. Parish, M. S. Shoichet, J. S. Forsythe, and D. R. Nisbet, "Biomaterials for brain tissue engineering," Australian Journal of Chemistry, vol. 63, no. 8, pp. $1143-1154,2010$.

[5] Y.-P. Lu, C.-H. Yang, J. A. Yeh et al., "Guidance of neural regeneration on the biomimetic nanostructured matrix," International Journal of Pharmaceutics, vol. 463, no. 2, pp. 177-183, 2014.

[6] B. Janković, J. Pelipenko, M. Škarabot, I. Muševič, and J. Kristl, "The design trend in tissue-engineering scaffolds based on nanomechanical properties of individual electrospun nanofibers," International Journal of Pharmaceutics, vol. 455, no. 1-2, pp. 338-347, 2013. 
[7] M. J. McClure, S. A. Sell, D. G. Simpson, B. H. Walpoth, and G. L. Bowlin, "A three-layered electrospun matrix to mimic native arterial architecture using polycaprolactone, elastin, and collagen: a preliminary study," Acta Biomaterialia, vol. 6, no. 7, pp. 2422-2433, 2010.

[8] X. Zhan, M. Gao, Y. Jiang et al., "Nanofiber scaffolds facilitate functional regeneration of peripheral nerve injury," Nanomedicine: Nanotechnology, Biology, and Medicine, vol. 9, no. 3, pp. 305-315, 2013.

[9] Z. Ma, M. Kotaki, R. Inai, and S. Ramakrishna, "Potential of nanofiber matrix as tissue-engineering scaffolds," Tissue Engineering, vol. 11, no. 1-2, pp. 101-109, 2005.

[10] I. P. Clements, Y.-T. Kim, A. W. English, X. Lu, A. Chung, and R. V. Bellamkonda, "Thin-film enhanced nerve guidance channels for peripheral nerve repair," Biomaterials, vol. 30, no. 23-24, pp. 3834-3846, 2009.

[11] S. K. Min, S. H. Kim, C. R. Kim, S. M. Paik, S. M. Jung, and H. S. Shin, "Effect of topography of an electrospun nanofiber on modulation of activity of primary rat astrocytes," Neuroscience Letters, vol. 534, no. 1, pp. 80-84, 2013.

[12] Y. I. Cho, J. S. Choi, S. Y. Jeong, and H. S. Yoo, "Nerve growth factor (NGF)-conjugated electrospun nanostructures with topographical cues for neuronal differentiation of mesenchymal stem cells," Acta Biomaterialia, vol. 6, no. 12, pp. 47254733, 2010.

[13] J. M. Corey, D. Y. Lin, K. B. Mycek et al., "Aligned electrospun nanofibers specify the direction of dorsal root ganglia neurite growth," Journal of Biomedical Materials Research-Part A, vol. 83, no. 3, pp. 636-645, 2007.

[14] E. Vatankhah, D. Semnani, M. P. Prabhakaran, M. Tadayon, S. Razavi, and S. Ramakrishna, "Artificial neural network for modeling the elastic modulus of electrospun polycaprolactone/gelatin scaffolds," Acta Biomaterialia, vol. 10, no. 2, pp. 709-721, 2014.

[15] T. B. Bini, S. Gao, X. Xu, S. Wang, S. Ramakrishna, and K. W. Leong, "Peripheral nerve regeneration by microbraided poly(Llactide-co-glycolide) biodegradable polymer fibers," Journal of Biomedical Materials Research Part A, vol. 68, no. 2, pp. 286295, 2004.

[16] M. P. Prabhakaran, L. Ghasemi-Mobarakeh, G. Jin, and S. Ramakrishna, "Electrospun conducting polymer nanofibers and electrical stimulation of nerve stem cells," Journal of Bioscience and Bioengineering, vol. 112, no. 5, pp. 501-507, 2011.

[17] W. Yu, W. Zhao, C. Zhu et al., "Sciatic nerve regeneration in rats by a promising electrospun collagen/poly( $\varepsilon$-caprolactone) nerve conduit with tailored degradation rate," BMC Neuroscience, vol. 12, article 68, 2011.

[18] W. Yu, X. Jiang, M. Cai et al., "A novel electrospun nerve conduit enhanced by carbon nanotubes for peripheral nerve regeneration," Nanotechnology, vol. 25, no. 16, Article ID 165102, 2014.

[19] Q. Zhang, Y. Yan, S. Li, and T. Feng, "The synthesis and characterization of a novel biodegradable and electroactive polyphosphazene for nerve regeneration," Materials Science and Engineering C, vol. 30, no. 1, pp. 160-166, 2010.

[20] J. M. Corey, C. C. Gertz, B.-S. Wang et al., "The design of electrospun PLLA nanofiber scaffolds compatible with serumfree growth of primary motor and sensory neurons," Acta Biomaterialia, vol. 4, no. 4, pp. 863-875, 2008.

[21] X. Jiang, H. Q. Cao, L. Y. Shi, S. Y. Ng, L. W. Stanton, and S. Y. Chew, "Nanofiber topography and sustained biochemical signaling enhance human mesenchymal stem cell neural commitment," Acta Biomaterialia, vol. 8, no. 3, pp. 1290-1302, 2012.

[22] J. Du, E. Tan, H. J. Kim, A. Zhang, R. Bhattacharya, and K. J. Yarema, "Comparative evaluation of chitosan, cellulose acetate, and polyethersulfone nanofiber scaffolds for neural differentiation," Carbohydrate Polymers, vol. 99, pp. 483-490, 2014.

[23] E.-R. Kenawy, G. L. Bowlin, K. Mansfield et al., "Release of tetracycline hydrochloride from electrospun poly(ethyleneco-vinylacetate), poly(lactic acid), and a blend," Journal of Controlled Release, vol. 81, no. 1-2, pp. 57-64, 2002.

[24] Y. Niu, K. C. Chen, T. He, W. Yu, S. Huang, and K. Xu, "Scaffolds from block polyurethanes based on poly( $\varepsilon$-caprolactone) (PCL) and poly(ethylene glycol) (PEG) for peripheral nerve regeneration," Biomaterials, vol. 35, no. 14, pp. 4266-4277, 2014.

[25] Y.-C. Kuo, S.-C. Hung, and S.-H. Hsu, "The effect of elastic biodegradable polyurethane electrospun nanofibers on the differentiation of mesenchymal stem cells," Colloids and Surfaces B: Biointerfaces, vol. 122, pp. 414-422, 2014.

[26] J. Gunn and M. Zhang, "Polyblend nanofibers for biomedical applications: perspectives and challenges," Trends in Biotechnology, vol. 28, no. 4, pp. 189-197, 2010.

[27] E. Masaeli, P. A. Wieringa, M. Morshed et al., "Peptide functionalized polyhydroxyalkanoate nanofibrous scaffolds enhance Schwann cells activity," Nanomedicine: Nanotechnology, Biology, and Medicine, vol. 10, pp. 1159-1569, 2014.

[28] D. I. Cha, K. W. Kim, G. H. Chu, H. Y. Kim, K. H. Lee, and N. Bhattarai, "Mechanical behaviors and characterization of electrospun polysulfone/polyurethane blend nonwovens," Macromolecular Research, vol. 14, no. 3, pp. 331-337, 2006.

[29] F. A. Sheikh, N. A. M. Barakat, M. A. Kanjwal et al., "Electrospun antimicrobial polyurethane nanofibers containing silver nanoparticles for biotechnological applications," Macromolecular Research, vol. 17, no. 9, pp. 688-696, 2009.

[30] B. Carlberg, M. Z. Axell, U. Nannmark, J. Liu, and H. G. Kuhn, "Electrospun polyurethane scaffolds for proliferation and neuronal differentiation of human embryonic stem cells," Biomedical Materials, vol. 4, no. 4, Article ID 045004, 2009.

[31] D. Gupta, J. Venugopal, M. P. Prabhakaran et al., "Aligned and random nanofibrous substrate for the in vitro culture of Schwann cells for neural tissue engineering," Acta Biomaterialia, vol. 5, no. 7, pp. 2560-2569, 2009.

[32] Q. P. Pham, U. Sharma, and A. G. Mikos, "Electrospinning of polymeric nanofibers for tissue engineering applications: a review," Tissue Engineering, vol. 12, no. 5, pp. 1197-1211, 2006.

[33] L. Binan, C. Tendey, G. de Crescenzo, R. El Ayoubi, A. Ajji, and M. Jolicoeur, "Differentiation of neuronal stem cells into motor neurons using electrospun poly-l-lactic acid/gelatin scaffold," Biomaterials, vol. 35, no. 2, pp. 664-674, 2014.

[34] A. Cooper, N. Bhattarai, and M. Zhang, "Fabrication and cellular compatibility of aligned chitosan-PCL fibers for nerve tissue regeneration," Carbohydrate Polymers, vol. 85, no. 1, pp. 149-156, 2011.

[35] H. Wang, Y. Feng, H. Zhao et al., "Electrospun hemocompatible PU/gelatin-heparin nanofibrous bilayer scaffolds as potential artificial blood vessels," Macromolecular Research, vol. 20, no. 4, pp. 347-350, 2012.

[36] J. Gunn and M. Zhang, "Polyblend nanofibers for biomedical applications: Perspectives and challenges," Trends in Biotechnology, vol. 28, no. 4, pp. 189-197, 2010. 
[37] D. Szarek, J. Laska, W. Jarmundowicz et al., "Influence of alginates on tube nerve grafts of different elasticity-preliminary in vivo study," Journal of Biomaterials and Nanobiotechnology, vol. 3, no. 1, pp. 20-30, 2012.

[38] D. Szarek, K. Marycz, P. Bednarz, P. Tabakow, W. Jarmundowicz, and J. Laska, "Influence of calcium alginate on peripheral nerve regeneration: in vivo study," Biotechnology and Applied Biochemistry, vol. 60, no. 5, pp. 547-556, 2013.

[39] S. K. Min, C. R. Kim, S. H. Kim, and H. S. Shin, "Assessment of morphology, activity, and infiltration of astrocytes on marine EPS-imbedded electrospun PCL nanofiber," Journal of Nanomaterials, vol. 2014, Article ID 302725, 8 pages, 2014.

[40] F. Roloff, S. Strauß, P. M. Vogt, G. Bicker, and C. Radtke, "Spider silk as guiding biomaterial for human model neurons," BioMed Research International, vol. 2014, Article ID 906819, 7 pages, 2014.

[41] G. C. W. de Ruiter, M. J. A. Malessy, M. J. Yaszemski, A. J. Windebank, and R. J. Spinner, "Designing ideal conduits for peripheral nerve repair," Neurosurgical Focus, vol. 26, no. 2, article E5, pp. 1-9, 2009.

[42] Y.-C. Huang and Y.-Y. Huang, "Biomaterials and strategies for nerve regeneration," Artificial Organs, vol. 30, no. 7, pp. 514-522, 2006.

[43] Y. Zhong and R. V. Bellamkonda, "Biomaterials for the central nervous system," Journal of the Royal Society Interface, vol. 5, no. 26, pp. 957-975, 2008.

[44] N. J. Hallab, K. J. Bundy, K. O’Connor, R. L. Moses, and J. J. Jacobs, "Evaluation of metallic and polymeric biomaterial surface energy and surface roughness characteristics for directed cell adhesion," Tissue Engineering, vol. 7, no. 1, pp. 55-71, 2001.

[45] M. P. Lutolf and J. A. Hubbell, "Synthetic biomaterials as instructive extracellular microenvironments for morphogenesis in tissue engineering," Nature Biotechnology, vol. 23, no. 1, pp. 47-55, 2005.

[46] K. R. Jessen and R. Mirsky, "Schwann cells and their precursors emerge as major regulators of nerve development," Trends in Neurosciences, vol. 22, no. 9, pp. 402-410, 1999.

[47] K. G. Wiese, D. E. Heinemann, D. Ostermeier, and J. H. Peters, "Biomaterial properties and biocompatibility in cell culture of a novel self-inflating hydrogel tissue expander," Journal of Biomedical Materials Research, vol. 54, no. 2, pp. 179-188, 2001.

[48] A. Honoré, S. Le corre, C. Derambure et al., "Isolation, characterization, and genetic profiling of subpopulations of olfactory ensheathing cells from the olfactory bulb," Glia, vol. 60, no. 3, pp. 404-413, 2012.

[49] P. Tabakow, W. Jarmundowicz, B. Czapiga et al., "Transplantation of autologous olfactory ensheathing cells in complete human spinal cord injury," Cell Transplantation, vol. 22, no. 9, pp. 1591-1612, 2013.

[50] J. Lu, F. Féron, A. Mackay-Sim, and P. M. E. Waite, "Olfactory ensheathing cells promote locomotor recovery after delayed transplantation into transected spinal cord," Brain, vol. 125, no. 1, pp. 14-21, 2002.

[51] H. Huang, L. Chen, H. Wang et al., "Influence of patients' age on functional recovery after transplantation of olfactory ensheathing cells into injured spinal cord injury," Chinese Medical Journal, vol. 116, no. 10, pp. 1488-1491, 2003.

[52] Y. Shen, Y. Qian, H. Zhang et al., "Guidance of olfactory ensheathing cell growth and migration on electrospun silk fibroin scaffolds," Cell Transplantation, vol. 19, no. 2, pp. 147-157, 2010.
[53] B. Wang, Y. Zhao, H. Lin et al., "Phenotypical analysis of adult rat olfactory ensheathing cells on 3-D collagen scaffolds," Neuroscience Letters, vol. 401, no. 1-2, pp. 65-70, 2006.

[54] A. Subramanian, U. M. Krishnan, and S. Sethuraman, "Development of biomaterial scaffold for nerve tissue engineering: biomaterial mediated neural regeneration," Journal of Biomedical Science, vol. 16, article 108, 2009.

[55] K. Marycz, D. Szarek, J. Grzesiak, and K. Wrzeszcz, "Influence of modified alginate hydrogels on mesenchymal stem cells and olfactory bulb-derived glial cells cultures," Bio-Medical Materials and Engineering, vol. 24, no. 3, pp. 1625-1637, 2014.

[56] K. Marycz, A. Śmieszek, J. Grzesiak, and J. E. Nicpoń, "Effects of steroids on the morphology and proliferation of canine and equine mesenchymal stem cells of adipose origin-in vitro research," Acta Veterinaria Hungarica, vol. 62, no. 3, pp. 317-333, 2014.

[57] A. Śmieszek, A. Donesz-Sikorska, J. Grzesiak, J. Krzak, and K. Marycz, "Biological effects of sol-gel derived $\mathrm{ZrO}_{2}$ and $\mathrm{SiO}_{2} / \mathrm{ZrO}_{2}$ coatings on stainless steel surface-in vitro model using mesenchymal stem cells," Journal of Biomaterials Applications, vol. 29, no. 5, pp. 699-714, 2014.

[58] M. Marędziak, K. Marycz, D. Lewandowski, A. Siudzińska, and A. Śmieszek, "Static magnetic field enhances synthesis and secretion of membrane-derived microvesicles (MVs) rich in VEGF and BMP-2 in equine adipose-derived stromal cells (EqASCs) - a new approach in veterinary regenerative medicine," In Vitro Cellular \& Developmental Biology-Animal, vol. 51, no. 3, pp. 230-240, 2015.

[59] Y. He, W. R. Wang, and J. D. Ding, "Effects of L-lactic acid and D,L-lactic acid on viability and osteogenic differentiation of mesenchymal stem cells," Chinese Science Bulletin, vol. 58, no. 20, pp. 2404-2411, 2013.

[60] Y. Yuan, P. Zhang, Y. Yang, X. Wang, and X. Gu, "The interaction of Schwann cells with chitosan membranes and fibers in vitro," Biomaterials, vol. 25, no. 18, pp. 4273-4278, 2004. 

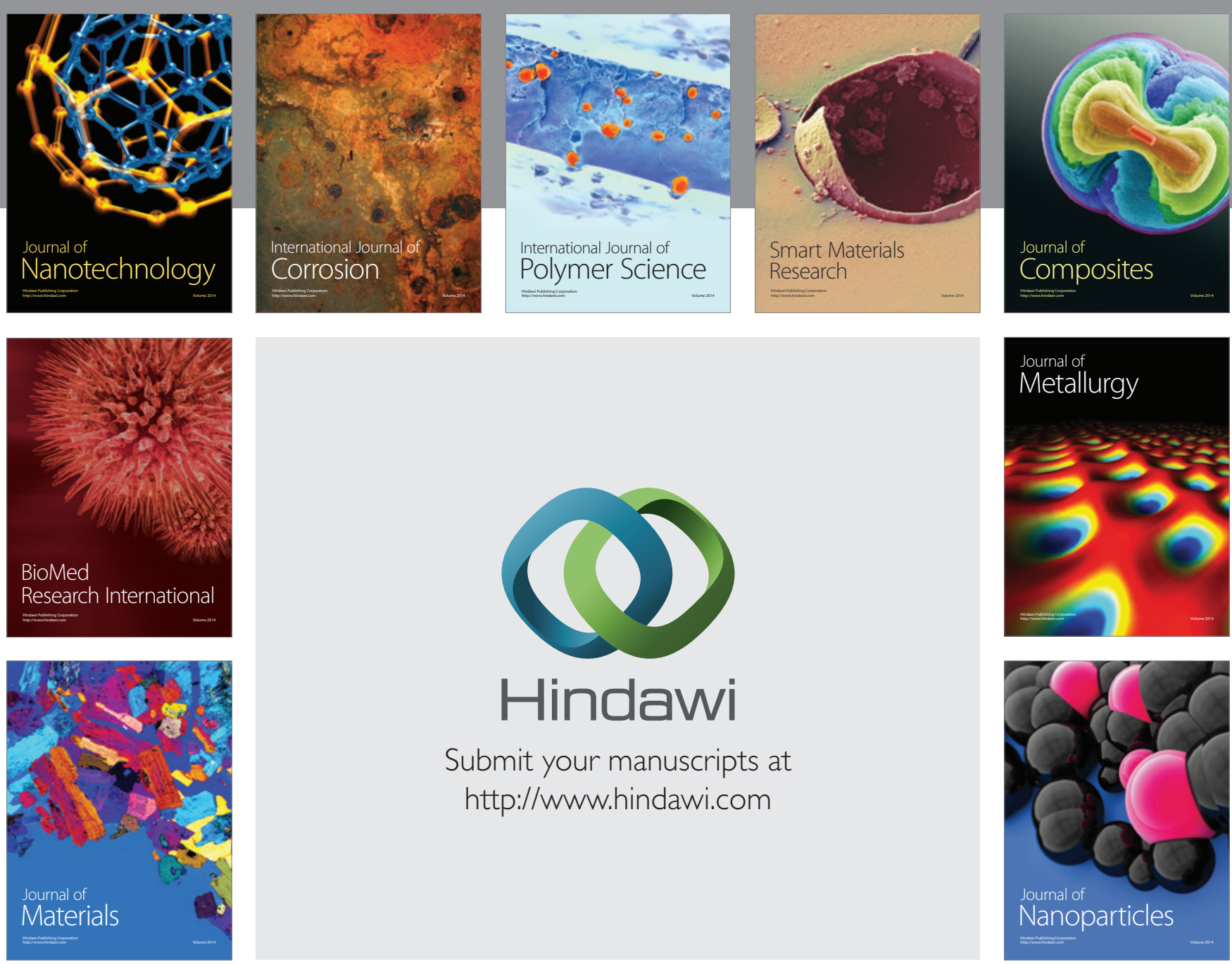

Submit your manuscripts at http://www.hindawi.com
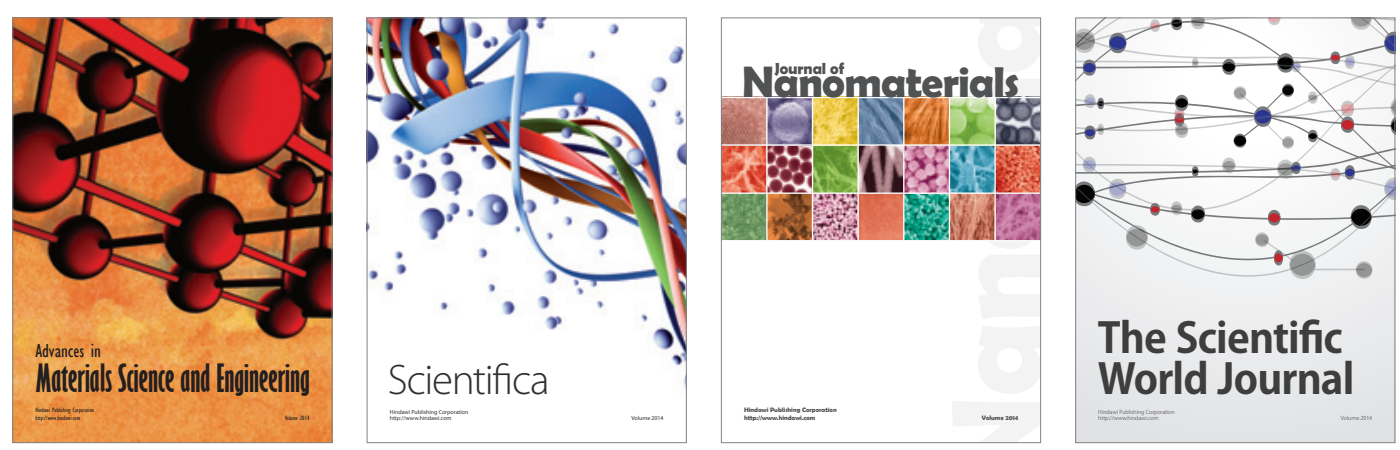

\section{The Scientific World Journal}
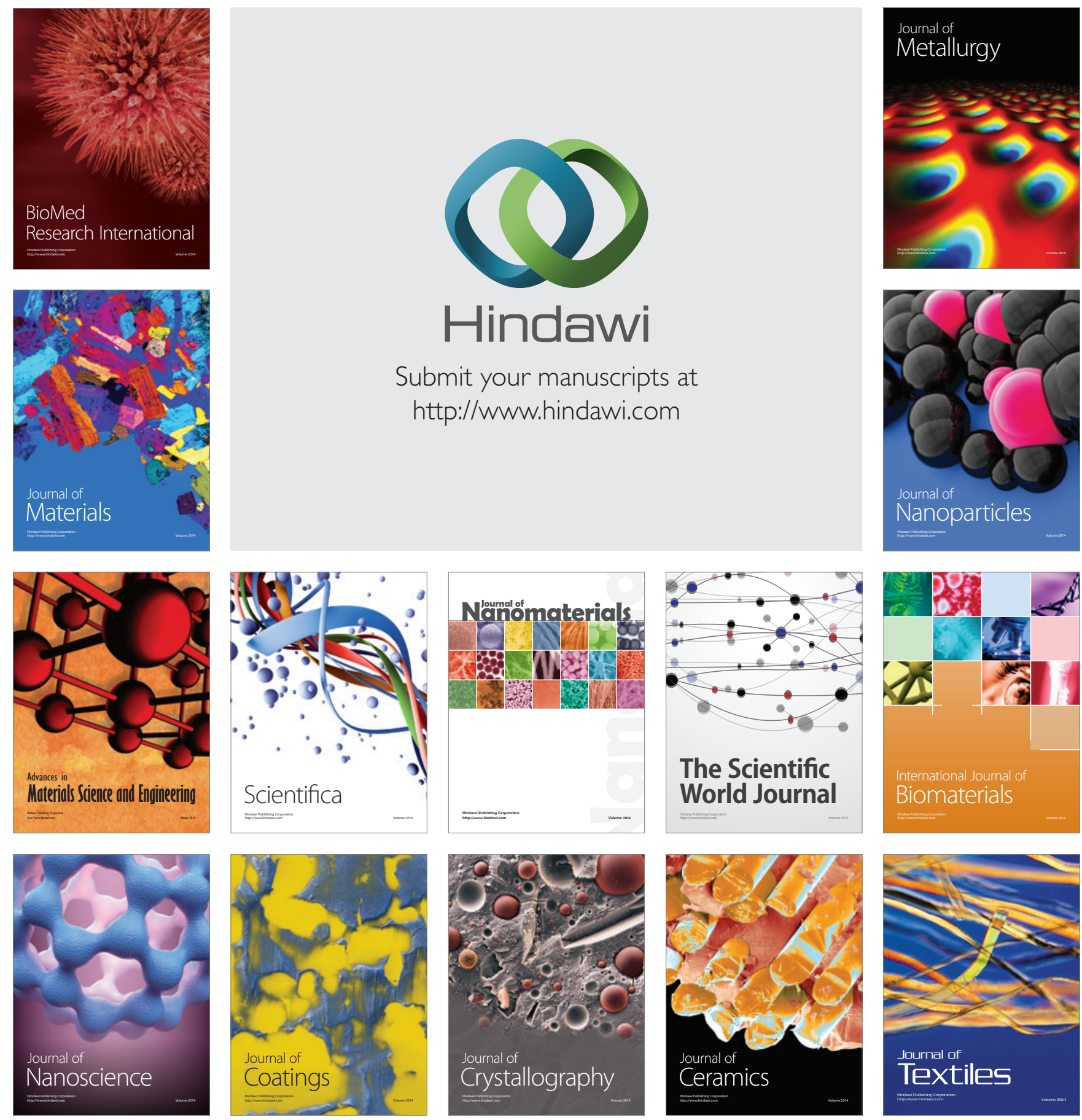